\title{
Preliminary results of surveys of normal and large uncoated petrographic specimens using variable pressure SEM with commercially-available automated imaging and X-Ray analysis (EDS) equipment.
}

Frederick C. Monson, Howell Bosbyshell and LeAnn Srogi, West Chester University, West Chester, PA, 19383, USA

Automation of analytic tasks in microscopy is a natural result of the increase of computer control that has been applied to the electron microscope over the past 15 years. Once control of Energy Dispersive Spectrometers (EDS) was ported from UNIX to Windows, it was natural to use the advantage of backscatter imaging in conjunction with Windows-based image-object analysis as the basis for automation of X-Ray analysis of specimens viewed with a SEM. We acquired a new variable pressure SEM (FEI Quanta 400 ESEM $^{\circledR}$ ) equipped with an integrated EDS system (Oxford $\mathrm{INCA}^{\circledR} 400$ with "Feature" and "Automate" (automated imaging modules)) in 2002. One of the first specimens presented was a petrographic section of a rock to locate monazite crystals in order to compare previous EPMA (Electron Probe MicroAnalysis) with EDS results acquired from the new platform. For this task we made use of the automation that had been purchased with the EDS system to locate all of the monazite crystals on the section ( 25 minutes beyond setup). Since the sections were already carbon coated, we first used the lowest pressure ("High Vacuum" on the Quanta) in BSE (BackScatter Electron) imaging mode. As is the case with old coatings, this one had breaks in inconvenient locations and we changed to variable pressure ("Low Vacuum" on the Quanta) to deal with the charging. It was quickly apparent that one could quickly survey a petrographic section in this higher pressure mode using the automated imaging and EDS analysis modules and postpone carbon coating until just prior to EPMA analysis.

There are two justifications for an automated 'survey' analysis: 1) to locate all of a large number of potentially valuable objects in order to define a reasonable number for further analysis (e.g., Figure 1, large and small garnet crystals which have intermediate gray scale levels); and 2) to locate a small number of objects in a large specimen (e.g., Figure 2, Thorium-Monazite Crystals(-)).

As an illustration of the first, we present some of the survey data as well as follow-up analysis on a large specimen rich in garnet (Figure 1, a montage of a diamond-sawed piece of rock rich in garnet). Table 1 shows the size distribution of garnet classes discovered on this specimen and reported by the INCA software following the survey for garnet on the specimen.

The use of the automated SEM/EDS image and analysis system to find suitable garnet inclusions, for example, is quick and certain, because of the gray scale signature of those inclusions. The next step was to use the relocation capability of the system to determine which of the 'found' garnet crystals merited further analysis. Each recognized feature of a specimen was stored as a record in an MS Access database with all accompanying microscope, elemental and morphometric data. The total number of objects enumerated in this analysis exceeded 1,800 and the time taken was about 3.5 hours. Subsequent to this automated analysis, several garnets were chosen to undergo extended mapping, most as single fields but one with montage mapping. The purpose of these maps was to determine the feasibility of further analysis with EPMA or to define zoning in a crystal.

Figure 3 is a pair of image montages taken from a rock specimen different from that shown in Figure 1. The first is composed of 16 backscatter images stitched to form an image of an entire garnet crystal. The second is composed of 16 elemental maps of Manganese (Mn) acquired from each of the 16 fields of the first montage. The montage map of Mn clearly shows that the distribution of $\mathrm{Mn}$ in the garnet is not uniform. The significance is beyond the scope of this report, 
but the key is to understand that in the Mn map, the brightness of the pixel is proportional to the amount of Manganese that was estimated from the X-Ray spectrum collected from the corresponding position on the specimen.

The use of automation under variable pressure conditions to analyze geologic specimens can increase the efficiency and productivity of the investigatory process that depends on scanning electron microscopy for the imaging and analysis of objects of $\mathrm{mm}$ interest.

Figure 1. Backscatter Montage of Large Garnet-Rich Specimen

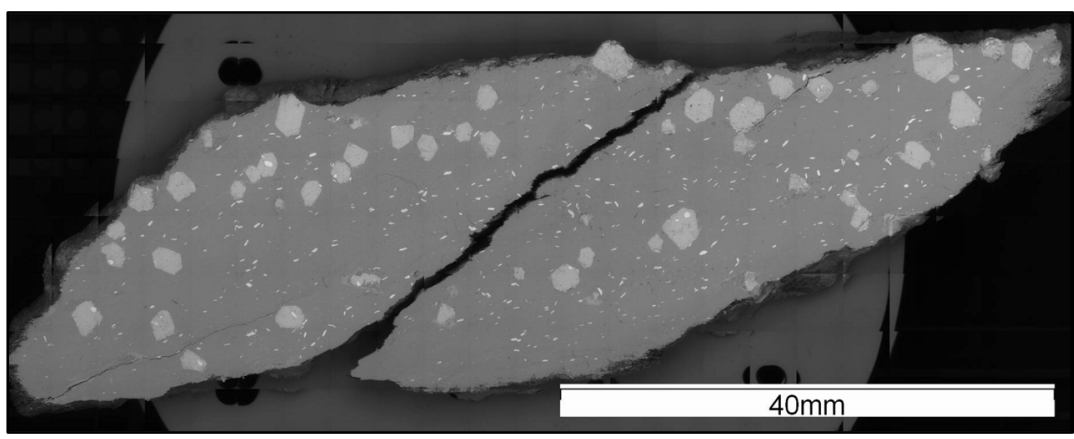

Table 1. Garnet Statistics from Automated Analysis

\begin{tabular}{|c|l|c|r|r|r|}
\hline $\begin{array}{c}\text { Class }(\boldsymbol{\mu m}) \\
\text { Diameter }\end{array}$ & Rank & Features & $\begin{array}{r}\text { \% total } \\
\text { features }\end{array}$ & $\begin{array}{c}\text { Feature area } \\
(\mathbf{s q} \cdot \boldsymbol{\mu m})\end{array}$ & $\begin{array}{c}\text { \% total } \\
\text { area }\end{array}$ \\
\hline Garnet $<100$ & GS-1 & 169 & 9.10 & 620,000 & 0.0270 \\
\hline Garnet $<150$ & GS-2 & 39 & 2.10 & 444,000 & 0.0190 \\
\hline Garnet $<200$ & GS-3 & 9 & 0.50 & 217,000 & 0.0093 \\
\hline Garnet $>200$ & GS-4 & 40 & 2.10 & $64,000,000$ & 2.7520 \\
\hline
\end{tabular}

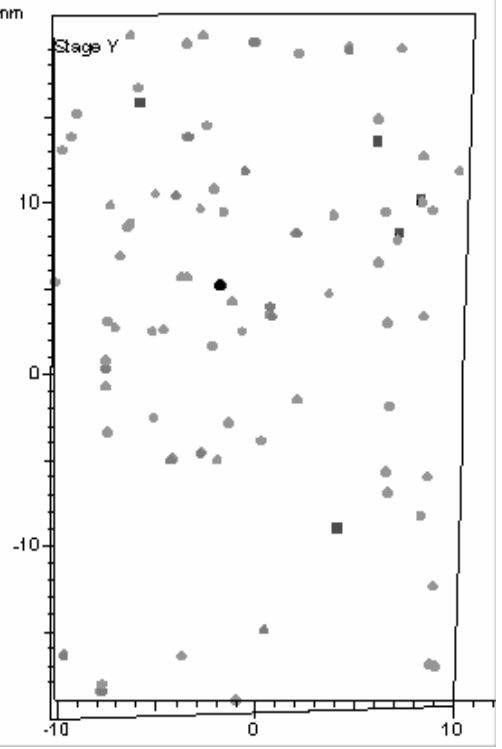

Figure 2. Scatter plot of distribution of ThoriumMonazite (-)and other Monazite Crystals $(\bullet)$ on a normal petrographic section.

Figure 3. Montage and Montage Map of Garnet - 16 Image Maps (4 x 4) were collected.

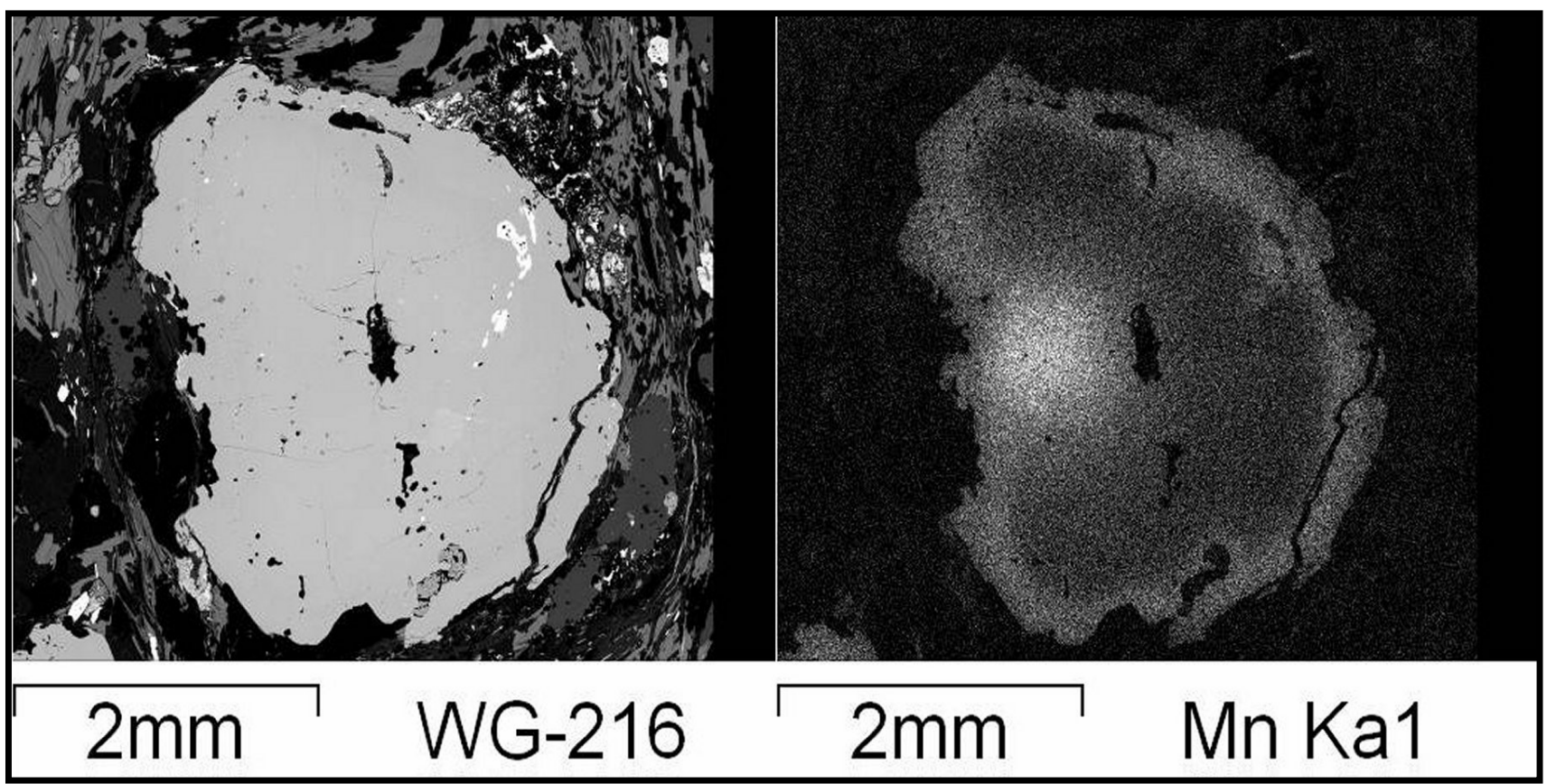

